\title{
An Uncommon Case of Isolated Superior Rectus Palsy
}

\author{
Teena Mariet Mendonca ${ }^{1,2, \odot}$ \\ ${ }^{1}$ Department of Ophthalmology, Kasturba Medical College, \\ Mangalore, India \\ 2 Manipal Academy of Higher Education, Manipal, India \\ ${ }^{3}$ Department of Radiology, Kasturba Medical College, \\ Mangalore, India
}

\author{
Gladys R. Rodrigues ${ }^{1,2}$ Shobha G. Pai ${ }^{1,2}$
}

J Neurosci Rural Pract:2020;11:484-486

\begin{abstract}
Keywords

- cranial nerve palsy

- head injury

- neuroimaging
\end{abstract}

\author{
Address for correspondence Teena Mariet Mendonca, MS, \\ Department of Ophthalmology, Kasturba Medical College Hospital, \\ Attavar, Mangalore, Karnataka, 575001, India \\ (e-mail: tmendonca87@gmail.com).
}

\section{Case Report}

A 14-year-old boy presented with history of head injury following a fall from his bicycle the previous day. He gave history of loss of consciousness for few minutes as well as bleeding from the nose. He also gave history of swelling around right eye and diplopia in upgaze. On examination, his visual acuity was $20 / 20$ in both eyes. Periorbital ecchymosis was present around his right eye. Anterior segment and fundus examination were both unremarkable. Extraocular motility evaluation revealed elevation limitation of about -3 in direct upgaze, dextro, and levo elevation in right eye (-Fig. 1). He was orthophoric in primary gaze and had 14 prism diopters of right hypotropia in upgaze. There was no evidence of enophthalmos or step deformity on palpation of the orbital rim. Clinically, we suspected orbital floor fracture with entrapment of the inferior rectus. However, forced duction test was negative.

Computed tomography of the orbits ( $2 \mathrm{~mm}$ sections) revealed no fracture of the orbital floor. However, there was orbital roof "blow in" fracture with fracture fragment impingement on the superior rectus muscle ( - Fig. 2). Hence, the patient was diagnosed to have paresis of superior rectus muscle due to impingement of fracture fragment on the nerve supplying superior rectus muscle.

The patient was observed for spontaneous recovery. On following up the patient after 2 weeks, elevation limitation had improved significantly. Subsequently, the elevation limitation resolved completely after a month.

\section{Discussion}

Isolated orbital roof fractures are relatively uncommon in adults accounting for only 1 to $9 \%$ of all facial bone fractures. ${ }^{1}$ High velocity injuries like motor vehicle accidents usually cause orbital roof fractures in association with other craniofacial injuries. ${ }^{2}$ In young children, orbital roof fractures are more common and can be caused by trivial trauma. ${ }^{3}$

The orbital roof is composed of frontal bone anteriorly and lesser wing of the sphenoid posteriorly. The term "blow out" fracture refers to fracture of the orbital floor or roof without involvement of the rim with fragments displaced away from the orbital cavity. Similarly, "blow in" fracture refers to displacement of the fracture fragments toward the orbital cavity without orbital rim fracture. "Blow in" fracture of the orbital roof could be a result of sudden increase in intracranial pressure or collapse of the orbital roof as a result of supraorbital blow directed inferiorly. ${ }^{4}$ Serious intracranial complications of orbital roof fractures are pulsatile exophthalmos and cerebrospinal fluid leak.

Patients with orbital roof fracture can present with limitation of upgaze and diplopia due to injury to the superior rectus muscle or injury to its nerve supply. As opposed to 

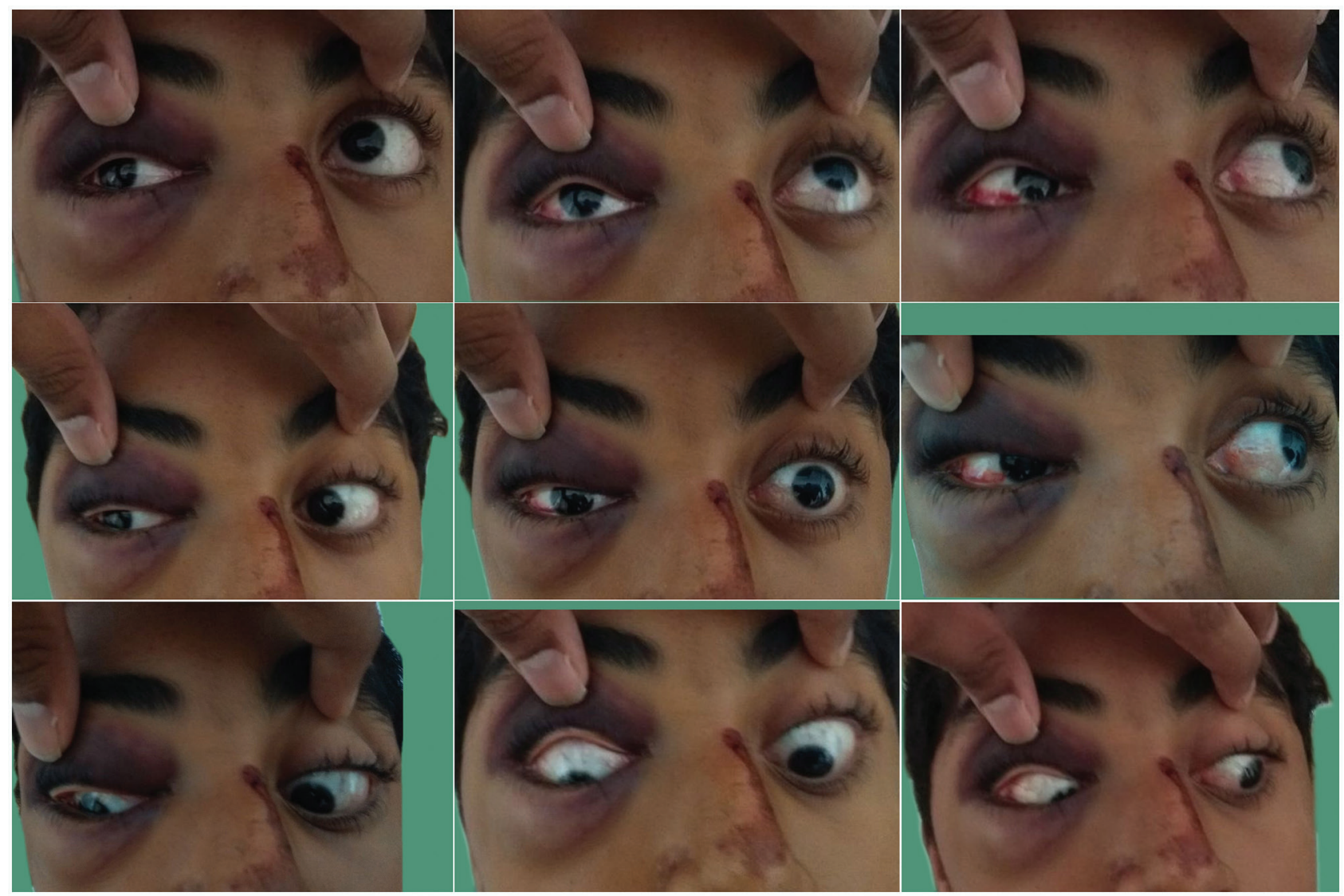

Fig. 1 Nine gaze photographs of the patient showing marked limitation of elevation in right eye.

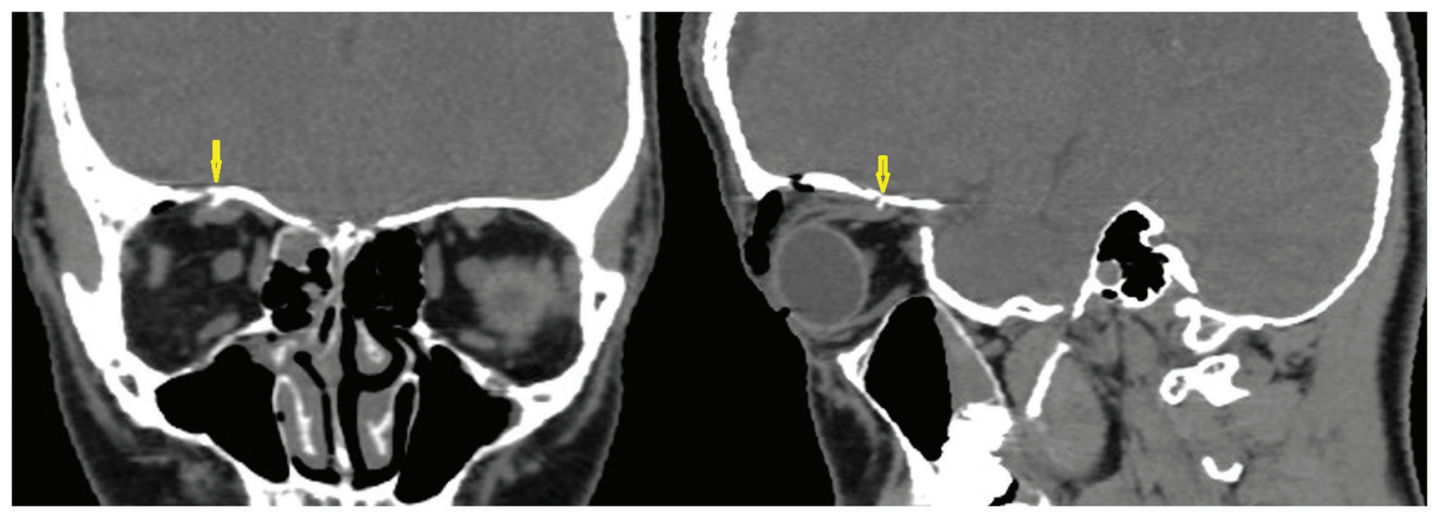

Fig. 2 Computed tomography of orbit coronal section (A) and sagittal section (B) showing "blow in " fracture of orbital roof with bone fragment impinging (arrow head) on superior rectus muscle.

entrapment of the extraocular muscle in blow out fractures, restriction of upgaze can occur due to bone fragments impinging on the superior rectus. ${ }^{5}$ Timothy et $\mathrm{al}^{2}$ have described 21 patients with orbital roof fracture with ophthalmic complications. However, injury to the superior rectus is not reported in their case series. In literature, various possible injuries to extraocular muscles and their causative mechanisms have been hypothesized. However, to our knowledge, "blow in" fracture of the orbital roof causing monocular elevation deficiency is not reported in literature. Since our patient recovered spontaneously, we presume that the site of injury could have been at the nerve supplying superior rectus by the bone fragments.

In conclusion, this case report highlights the importance of orbital imaging and careful evaluation of thin sections of computed tomography orbit in cases of orbital trauma.

\section{Note}

The study was conducted at Kasturba Medical College Hospital, Attavar, Mangalore, Karnataka, India.

\section{Conflict of interest}

None declared. 


\section{References}

1 Haug RH, Van Sickels JE, Jenkins WS. Demographics and treatment options for orbital roof fractures. Oral Surg Oral Med Oral Pathol Oral Radiol Endod 2002;93(3):238-246

2 Fulcher TP, Sullivan TJ. Orbital roof fractures: management of ophthalmic complications. Ophthal Plast Reconstr Surg 2003;19(5):359-363
3 Oppenheimer AJ, Monson LA, Buchman SR. Pediatric orbital fractures. Craniomaxillofac Trauma Reconstr 2013;6(1):9-20

4 Jones AL, Jones KE. Orbital roof "blow-in" fracture: a case report and review. J Radiol Case Rep 2009;3(12):25-30

5 McLachlan DL, Flanagan JC, Shannon GM. Complications of orbital roof fractures. Ophthalmology 1982;89(11):1274-1278 